\title{
Environmental Factors and Children's Malnutrition in Ethiopia
}

\author{
Patricia Silva \\ World Bank, Environment Department
}

\begin{abstract}
Ethiopia has one of the highest child malnutrition rates in the world. A considerable effort to monitor child malnutrition rates over the last two decades shows that, despite some improvements, approximately half of the children under five are still malnourished. Much of the burden of deaths resulting from malnutrition, estimated to be over half of childhood deaths in developing countries, can be attributed to just mild and moderate malnutrition. Several biological and social economic factors contribute to malnutrition. Using the 2000 Ethiopia Demographic and Health Survey data, this study examines the impact of access to basic environmental services, such as water and sanitation, on the probability children are stunted and underweight. The focus is on the impact of externalities associated with access to these services. We find that biological factors, such as child's age and mother's height, and social economic factors, such as household wealth and mother's education, are important determinants of a child's nutritional status. This is consistent with the findings of most studies in this literature. With respect to the environmental factors, we find that there are indeed significant externalities associated with access to water and sanitation at the community level. The external impacts of community level of access to these services are an important determinant of the probability a child is underweight. Our results also show that the external impact of access to water is larger for children living in rural areas.
\end{abstract}

World Bank Policy Research Working Paper 3489, January 2005

The Policy Research Working Paper Series disseminates the findings of work in progress to encourage the exchange of ideas about development issues. An objective of the series is to get the findings out quickly, even if the presentations are less than fully polished. The papers carry the names of the authors and should be cited accordingly. The findings, interpretations, and conclusions expressed in this paper are entirely those of the authors. They do not necessarily represent the view of the World Bank, its Executive Directors, or the countries they represent. Policy Research Working Papers are available online at http:/lecon.worldbank.org.

\section{Acknowledgements}

We are grateful to the Trust Fund for Environmentally and Socially Sustainable Development for generous financial support. Thanks also goes to Kirk Hamilton, Team Leader, Policy and Economics Team for his support, and to Harold Alderman, Sushenjit Bandyopadhyay, Rama Chandra Reddy, Luc Christiaensen, and Limin Wang for useful discussion and valuable comments provided. 


\section{Introduction}

Ethiopia has one of the highest child malnutrition rates in the world. A considerable effort to monitor child malnutrition rates over the last two decades shows that, despite some improvements, approximately half of the children under five are still malnourished (Alderman and Christiaensen, 2001). Much of the burden of deaths resulting from malnutrition, estimated to be over half of childhood deaths in developing countries, can be attributed to just mild and moderate undernutrition. ${ }^{1}$ Underweight children are particularly vulnerable to increased risk of death from infectious illnesses such as diarrhea and pneumonia (WHO, 2002). For those children that do survive, the impact of chronic malnutrition in the first few years of life are long lasting and can lead to cognitive and physical developmental deficits, higher levels of chronic illness and disability in adult life (resulting in reduced work capacity), as well as adverse pregnancy outcomes (low birth weight).

Several biological and social economic factors contribute to malnutrition. A conceptual framework developed by UNICEF, and extended by Engle, Menon, and Haddad (1997), recognizes three levels of determinants of children's nutritional status. The immediate determinants of children's nutritional status are dietary intake and health status. These are in turn influenced by underlying determinants: food security, adequate care for mothers and children, and a proper healthy environment, which includes the availability of safe water, sanitation, health care, and environmental safety. The ability of households to translate resources to achieve food security, care, and a healthy environment are limited by political, economic, cultural, and social factors at the community and national level, which are the basic determinants of children's nutritional status (Smith and Haddad, 1999).

Previous studies have concentrated on the impacts of several of the underlying determinants, particularly maternal education and access to health care, on malnutrition rates. Maternal education, which is often used as a proxy for the quality of care received by children, is identified as a key determinant of nutritional outcomes. Maternal education can

\footnotetext{
${ }^{1}$ Pelletier (1994) is the source of this much quoted statistic. The analysis in the current World Health Report estimates the deaths of 3.7 million young children in 2002 were related to malnutrition. The World Health Organization benchmark considers the proportion of children whose weight for age score falls one standard deviation below the standardized population mean and a woman's body mass index below 20 to be mildly malnourished.
} 
influence nutritional outcomes through several channels, such as directly transmitting health knowledge to mothers, teaching numeracy and literacy skills needed to diagnose and appropriately treat common child health problems, and exposing women to modern medical treatment (Glewwe, 1999). Education can also raise women's self-confidence and status in the household, enabling women to take a more active and effective role in intra-household decision making and in obtaining health care assistance (Smith and Haddad, 1999; Alderman, Hentschel, and Sabates, 2002). Several other recent studies support these findings with regard to the important role of maternal education (Gragnolati, 1999; Christiansen and Alderman 2001; Sahn and Stifel, 2002).

Thomas and Strauss (1992) focus on the impacts of community infrastructure (piped water, sewerage, and health care) and local market conditions (prices for six food groups) on children's height in Brazil. They find that water and sewerage facilities significantly affect children's height, particularly for older children in urban areas. These results do not hold for rural areas, where the lack of access to modern infrastructure makes it difficult to measure a "healthy environment." They emphasize the importance of controlling for the effects of community infrastructure to obtain unbiased estimates of the impacts of maternal education and income on children's health. Recent development in the literature examines the impact of other households' investments in education (Glewwe, 1999; Alderman, Hentschel, and Sabates, 2002) and water and sanitation infrastructure, on children's health (Alderman, Hentschel, and Sabates, 2002). Of particular interest in this line of investigation are the potential positive externalities in the production of children's health associated with the decision of neighboring households to invest in education and water and sanitation services.

The focus of the current study is to examine the impact of externalities associated with access to water and sanitation services, for which the empirical evidence so far has been mixed. Gragnolati (1999), for example, finds that the proportion of households with access to piped water has a positive impact on Guatemalan children's nutritional status (measured by stunting). However, the opposite outcome is found for access to sanitation. Alderman, Hentschel, and Sabates (2002) find that impact of sanitation investments in the neighborhood dominate both the impact of sanitation and piped water investments at the household level, with rural households being more likely to benefit from their neighbor's investments in both services. We examine the relationship between access to water and sanitation services at the 
household and neighborhood level on children's nutritional status, controlling for the effects of important determinants of nutritional status identified in the literature. Data from the 2000 Ethiopia Demographic and Health Survey (DHS) are used for the analysis, which estimates the probability of children being stunted and underweight.

The paper is structured as follows. Section 2 describes the Ethiopia DHS dataset used for the analysis. Section 3 focuses on the problem of malnutrition in Ethiopia and provides some statistics on the demographic and geographical characteristics of the surveyed population. Section 4 introduces the theoretical framework adopted for the analysis, which follows Alderman, Hentschel, and Sabates (2002), and the empirical strategy employed. Section 5 discusses the econometric specification of the model and the econometric issues that arise in the estimation of the specified model. Section 6 presents the results of the analysis. Section 7 concludes.

\section{The Ethiopia Survey}

The 2000 Ethiopia DHS is a comprehensive, nationally representative population and health survey conducted in Ethiopia. ${ }^{2}$ The survey interviewed 15,367 women between 15 and 49 years of age to collect information regarding fertility and family planning behavior, child mortality, children's nutritional status, the utilization of maternal and child health services, and knowledge of HIV/AIDS and STDs. The survey was carried by the Central Statistical Authority (CSA), with technical assistance provided by ORC Macro as a part of its MEASURE DHS+ project. The survey took place between February and May 2000, following the harvesting season of the main Meher crops, maize and sorghum, which account for 90 to 95 percent of total cereal production.

A two-stage sampling procedure was adopted, using the 1994 Population and Housing Census as the sampling frame. In the first stage, 540 enumeration areas (EA)-139 in urban areas and 401 in rural areas-were selected using systematic sampling with probabilities proportional to the population size. A listing of all households in each of the selected EA was produced and 27 households per EA were selected in all regions in the second stage. This

\footnotetext{
${ }^{2}$ The information concerning the survey described in this section comes from the Ethiopia Demographic and Health Survey 2000 report produced by the Central Statistical Authority and ORC Macro.
} 
resulted in a total of 10,449 observations. The two stage sampling procedure adopted ensures that statistically reliable estimates of key demographic and health variables are available for all regions of Ethiopia. ${ }^{3}$

The Ethiopia DHS used three questionnaires for the survey. The household questionnaire collects information on basic socioeconomic characteristics of all household members, such as the age, sex, marital status, education, and so on. It also includes information on the dwelling, such as the floor, ceiling, wall materials, and the number of rooms; the source of drinking water and the type of toilet facilities used by the household; as well as ownership of a variety of durable assets. The women's questionnaire collects information on reproductive history; contraceptive use and knowledge; fertility preferences; antenatal, delivery, and postnatal care; infant feeding practices, child immunization and health; among other things. All eligible women (15-49 years of age) and children born after September 1994 were weighed and measured. Finally, the males' questionnaire interviews eligible males (15-59 years of age) in every fifth household to collect information on the respondent's background; contraceptive knowledge and use; marriage; fertility preferences; attitudes about family planning; and knowledge of HID/AIDS and STDs. Interviews were completed for 99 percent of occupied households, with no difference in the overall response rate for urban and rural eligible women. Rural men were slightly more likely than urban men to have completed an interview.

\section{Malnutrition in Ethiopia}

The Ethiopia DHS data add to the vast and growing international database on demographic and health variables collected as a part of the MEASURE DHS+ project. These surveys have been carried out in 32 countries in Sub-Saharan Africa, facilitating the comparison of malnutrition indicators among low income countries in the region. In a wellnourished population, the distribution of children's height and weight at a given age approximates a normal distribution. For comparison purposes, children's height and weight

\footnotetext{
${ }^{3}$ The sample population in Affar and Somali excluded the nomadic population and therefore some bias in the representativeness of the regional estimates for these two regions may occur. However, the population in these two regions relative to the country as a whole is small and it is unlikely the sampling strategy affects the reliability of the national and urban-rural estimates.
} 
measurements are standardized according to the International Referenced Population defined by the U.S. National Center for Health Statistics. The three commonly used indicators of malnutrition are height-for age, weight-for-age, and weight-for height. Children whose measurements fall below two standards deviations from the reference median are generally considered malnourished. Each indicator captures different aspects of malnutrition.

Stunting, or low height for age, is considered an indicator of chronic malnutrition. Height for age measures linear growth and therefore a low score is indicative of a cumulative growth deficit. Stunting is often the result of inadequate feeding practices over a long period and/or repeated illness. It is likely to persist even after these conditions are eliminated. Wasting, or low weight-for-height, measures body mass in relation to body length and is generally considered to reflect acute malnutrition. As an indicator, wasting is likely to vary over short periods of time due to food availability and disease prevalence. Underweight, or low weight for age, is a composite of height for age and weight for height. It is generally considered a general indicator of malnutrition, since a child that is underweight could be stunted or wasted, or both stunted and wasted.

Table 1 compares the proportion of children malnourished, according to the definitions discussed above, in Ethiopia and other low-income Sub-Saharan countries. The data used to calculate the indicator averages for low income Sub-Saharan countries include all countries for which DHS data for children under five years of age was available over the past decade. ${ }^{4}$ If more than one survey was available for a given country, only data from the most recent survey was included. Compared to other low-income Sub-Saharan countries, Ethiopia has the second highest rate of stunting and underweight. The proportion of children stunted is 50 percent higher than the average for those countries. In general, children in rural areas are more likely to be stunted than children in urban areas. The difference between the proportion of children underweight is also significantly higher. However, comparisons between the proportion of children underweight and wasted needs to be qualified, as different surveys took place in different years. Restricting the sample to surveys that took place between 1999 and 2001, however, does not significantly affect the regional average for these indicators. It is also

\footnotetext{
${ }^{4}$ We restricted the sample to surveys carried out since 1991. Some DHS datasets only collected children's measurement data for children under 3 years of age. Since the Ethiopia dataset includes these measurements for all children under five, we chose to make the comparison with similar datasets. Alternatively we could have chosen to restrict the samples to children under 3 years of age only, then all data would be comparable.
} 
worth noting that during 1999/2000, Ethiopia suffered its worst food crisis since the 1984/85 famine. We do not have information to what extent other countries may or may not have faced a similar crisis.

Table 1. Malnutrition Indicators Across Sub-Saharan Africa

\begin{tabular}{llccc}
\hline & & Rural & Urban & Full Sample \\
\hline Ethiopia (2000) & Stunted & 52.3 & 41.6 & 51.2 \\
& Underweight & 48.6 & 34.0 & 47.1 \\
& Wasted & 11.3 & 5.4 & 10.7 \\
Average for Low Income & Stunted & 37.0 & 25.7 & 34.1 \\
Sub-Saharan Countries & Underweight & 28.3 & 18.0 & 25.9 \\
& Wasted & 8.0 & 6.2 & 7.5 \\
& & & & \\
\hline
\end{tabular}

Note: countries included and the year the survey took place are: Benin (2001), Burkina Faso (1998/99), Cameroon (1991), Chad (1996/97), Cote d'Ivory (1998/99), Ghana (1998), Guinea (1999), Kenya (1993), Madagascar (1992), Malawi (2000), Mauritania (2000/01), Namibia (1992), Niger (1992), Nigeria (1990), Rwanda (1992), Senegal (1992/93), Tanzania (1999), Uganda (2000/01), Zambia (1996), Zimbabwe (1999)

The discussion now focuses on the prevalence of malnutrition inside Ethiopia. Table 2 shows the geographical variation in the prevalence of children stunted and underweight. Addis Ababa and Dire Dawa, the most urbanized areas of Ethiopia, show a considerably lower rate of malnourished children. In Tigray and Ahmara, in the northern part of Ethiopia, and the Southern Nations, Nationalities and People (SNNP) more than half of the children are malnourished. Several factors impacting food production, such as primitive agriculture practices, recurrent droughts, and long lasting civil wars, contribute to the high prevalence of malnutrition in Ethiopia. It is worth noting, however, that some of the regions with the highest rates of malnutrition are also the food surplus regions of the country (Haidar and Demissie, 1999). While food production is an important factor, it is does not necessarily ensure household food security. Also, as Alderman and Garcia (1994) stress, household food security alone is not sufficient to improve the children's nutritional status. 
Table 2. Malnutrition Indicators for Ethiopia, by Region

\begin{tabular}{|c|c|c|c|c|c|}
\hline & \multicolumn{2}{|c|}{ Height for Age } & \multicolumn{2}{|c|}{ Weight for Age } & \multirow[b]{2}{*}{$\begin{array}{l}\text { Number of } \\
\text { Children }\end{array}$} \\
\hline & $\begin{array}{c}\% \text { below } \\
-2 \mathrm{SD}\end{array}$ & Mean $\mathrm{Z}$ & $\begin{array}{c}\% \text { below } \\
-2 \text { SD }\end{array}$ & Mean Z & \\
\hline \multicolumn{6}{|l|}{ Residence } \\
\hline Urban & 41.6 & -1.7 & 34.0 & -1.4 & 1,067 \\
\hline Rural & 52.3 & -2.1 & 48.6 & -1.9 & 9,328 \\
\hline \multicolumn{6}{|l|}{ Region } \\
\hline Tigray & 55.3 & -2.1 & 47.9 & -1.9 & 689 \\
\hline Affar & 47.6 & -1.9 & 50.5 & -1.9 & 94 \\
\hline Amhara & 57.0 & -2.3 & 51.8 & -2.0 & 2712 \\
\hline Oromiya & 47.2 & -1.9 & 42.4 & -1.7 & 4288 \\
\hline Somali & 46.2 & -1.7 & 44.3 & -1.6 & 83 \\
\hline Benishngul-Gumuz & 41.3 & -1.7 & 42.3 & -1.7 & 101 \\
\hline SNNP & 55.4 & -2.3 & 53.7 & -2.0 & 2237 \\
\hline Gambela & 37.0 & -1.3 & 39.0 & -1.6 & 23 \\
\hline Harari & 37.3 & -1.5 & 27.1 & -1.4 & 21 \\
\hline Addis Ababa & 26.8 & -1.1 & 14.1 & -0.9 & 165 \\
\hline Dire Dawa & 30.5 & -1.1 & 30.8 & -1.3 & 36 \\
\hline
\end{tabular}

Notes: Reported means are adjusted for sample probabilities

The two most important risk factors contributing to malnutrition are insufficient food intake and repeated infectious illnesses. Table 3 shows the proportion of children malnourished and with diarrhea and fever by age groups and by the mother's level of education. The proportion of children malnourished increases significantly with ageparticularly between the first and second year of life. The World Health Organization (WHO) recommends exclusive breastfeeding for children under 6 months and the introduction of solid and semi-solid food around the age of 6 months. The Ethiopia data shows that most children under the age of 6 months are predominantly breastfed, although only about a third are exclusively breastfed, as it is recommended by the WHO.

The mother's education level is likely to be a significant factor influencing child feeding practices. The data show the introduction of other liquids takes place earlier than at the suggested 6 months of age-with children as young as 2 months of age consuming other liquids. Almost thirty percent of children under 6 months are also given plain water or other water based liquids or juices. The children of mothers with a primary education are breastfed 
more frequently, although there are no significant differences in the length of breastfeeding between mothers with no education and primary education.

It is somewhat more difficult to assess the adequateness of feeding practices at older ages, since this choice may be significantly restricted by food availability. The data show that only 44 percent of children between 6-9 months of age are consuming solid or semi-solid foods, as recommended. By 12 months, 85 percent of children are consuming solid or semisolid foods. Their diet consists mostly of foods made from cereals and legumes — only a third of the children 12 months of age are consuming vitamin A rich foods. Food availability may be a significant factor why less than 3 percent of children stop breastfeeding by 12 months.

Table 3 also shows the prevalence of diarrhea and fever-the two most common symptoms of childhood infectious diseases. Fever, in particular, is usually a manifestation of malaria or other acute infectious disease. Both fever and diarrhea are major contributors to child mortality and high levels of malnutrition. The prevalence of diseases and malnutrition are interrelated, as diseases tend to reduce the appetite and interfere with the digestion and absorption of food consumed. This in turn exacerbates malnutrition, which makes the child more vulnerable to diseases, such as diarrhea and other infectious diseases. ${ }^{5}$

The proportion of children with diarrhea more than doubles as the child reaches 6 months of age. The highest rate of diarrhea incidence - around 38 percent-occurs in children in the 6-11 and 12-23 months age groups. Two factors may explain this increase in the incidence of diarrhea. First, children at this age are beginning consumption of other foods and may therefore be ingesting contaminated food or liquids. Second, children at this age are becoming more mobile and therefore may come into contact with potential hazards in their surroundings. A major risk factor in spreading infectious diseases are improperly disposed human feces. If feces are left uncontained, disease may spread either by direct contact or animal contact with feces. Seventy-seven percent of households do not dispose of children's stool properly by throwing it in a toilet/latrine or burying it in the yard. The availability of

\footnotetext{
5 The figures reported in table 3 rely on the mothers' recall of whether the child showed symptoms of the respective illnesses in the two weeks prior to the survey. It therefore may be subject to recall bias, as well as possible misdiagnosis.
} 
toilet facilities clearly impacts the way a household disposes of children's stool and 85 percent of the households surveyed do not have access to any sanitation facilities.

Children 6-11 and 12-23 months of age are also more commonly sick with fever-40 and 35 percent, respectively. There are significant regional variations in the prevalence of fever, particularly in areas where malaria is more common (Affar and Gambela regions). Very few children with fever are taken to a health facility or provider for treatment. The mother's level of education does not seem to influence the prevalence of children with fever. However, children of mothers with a secondary education are 7 percent less likely to have diarrhea than children of mothers with no education. More importantly, children of mothers with a secondary education are almost 3 times more likely to be taken to a health provider when they have diarrhea and are 50 percent more likely to receive oral hydration therapy.

Table 3. Malnutrition and Prevalence of Infectious Diseases

\begin{tabular}{lcccc}
\hline & Stunting & Underweight & Diarrhea & Fever \\
\hline Child's age (months) & & & & \\
$<6$ & 10.6 & 6.6 & 15.4 & 25.7 \\
$6-11$ & 28.7 & 37.4 & 38.5 & 39.5 \\
$12-23$ & 57.2 & 56.1 & 37.1 & 35.4 \\
$24-35$ & 56.1 & 54.8 & 26.2 & 29.4 \\
$36-47$ & 60.7 & 49.6 & 16.1 & 24.1 \\
$48-59$ & 60.1 & 50.1 & 11.8 & 20.2 \\
& & & & \\
Mothers education & & & & \\
No education & 52.9 & 49.6 & 24.4 & 28.3 \\
Primary & 49.1 & 40.4 & 21.4 & 28.1 \\
Secondary and higher & 32.9 & 27.7 & 17.1 & 29.8 \\
\hline
\end{tabular}

\section{Empirical Strategy}

The main objective of the analysis is to estimate the impact of access to water and sanitation services on children's nutritional status, while controlling for the effects of important determinants of nutritional status identified in the literature. In addition to estimating the impact of household access to water and sanitation services, the analysis also examines the additional impact the proportion of households with access to these services has 
on the nutritional status of children. The approach adopted closely follows Alderman, Hentschel, and Sabates' (2002) analysis of the nutritional status of children in Peru.

Model

The nutritional status of a child is assumed to be a function of household inputs, such as nutrients $(F$, food), health $(H)$, and child care $(C)$. The nutritional production function can be written as:

(1) $N_{i}=N\left(F_{i}, H_{i}, C_{i}, E, e_{i}, \varepsilon\right)$

where $E$ represents observed neighborhood environmental conditions, $e_{i}$ represents unobserved child specific characteristics, and $\varepsilon$ unobserved community effects.

Nutritional production functions, however, are rarely estimated. This is because inputs that go into the nutritional production function are likely to be endogenously determined. ${ }^{6}$ Instead, the approach generally adopted is to estimate a nutritional demand equation. To derive this demand equation, we assume households maximize utility over consumption goods $(G)$, leisure $(L)$, and the nutritional status of members of the household $(N)$ :

(2) $U=u(G, L, N)$

subject to the above nutritional production function, time and budget constraints, to yield a nutritional demand function such as:

(3) $N_{i}=n\left(Y_{i}, E, \varepsilon, \mu_{i}\right)$

Where $Y$ represents household resources, $E$ environmental conditions, $\varepsilon$ unobserved community effects, and $\mu$ is a random error term, which includes unobserved individual characteristics $e_{i}$, as well as measurement error. Nutrient and health inputs are not included in the above equation - only factors which affect the level and efficiency by which these inputs are used are included. Clearly missing in the above demand equation are any relevant prices.

\footnotetext{
${ }^{6}$ Some important child specific characteristics, such as length of breastfeeding, preceding birth interval, as well as partial information on food intake and health history are available in the Ethiopia DHS dataset. However, to be able to use these variables, a number of econometric issues must be overcome.
} 
However, since prices are not likely to vary in a community and there is no time variation with cross sectional data, it could be argued that price effects get subsumed into $\varepsilon$, the unobserved community effects (Alderman, Hentschel and Sabates, 2002). How the data from the Ethiopia DHS is used to construct these variables is explained next.

\section{Variables}

Data from the Ethiopia DHS constitute the primary basis for the empirical analysis of the present study. The discussion here focuses on how this data has been used to construct variables used to proxy for $Y$, household resources, and $E$, environmental conditions, in equation (3) above.

\section{$\underline{\text { Individual characteristics }}$}

Several control variables are included to control for heterogeneity at the individual level. Individual specific controls include the child's gender, age, and the mother's height. The age variable is included as a dummy variable for different age groups to control for the cumulative effect of malnutrition. Mother's height is included to proxy for the child's genetic endowment. Previous research suggests mother's height is associated with a child's birth weight and has a stronger impact on a child's height than father's height.

\section{$\underline{\text { Household resources }}$}

No income or expenditure data is collected as a part of the DHS surveys. In the absence of such data, Filmer and Prichett (1998) have suggested the use of a wealth index, which can be constructed from information regarding housing characteristics and the possession of household durable goods. This is approach adopted in this study. The wealth index serves as a proxy for the household's long-run wealth or economic status. Its reliability is dependent on having the appropriate weights for the assets. Using principal component analysis, factor scores are generated for each type of asset and determine the weight these assets receive in the construction of the asset based wealth index. The idea is to extract from a large number of variables the orthogonal linear combinations of the variables that best capture the largest amount of information common to all of the variables (Filmer and Pritchett, 1998). 
Very poor households, however, may not acquire many durable goods and spend most of their income on consumption, particularly food consumption. Therefore a more complete assessment of the household's wealth would need to include a consumption measure as well. Even when available, household food related expenditure or consumption data is an imperfect measure of welfare, as it does not take into account seasonal changes, the distribution of food within the household, and the variability of all individual household members needs. An alternative is to use an outcome based indicator that would reflect how these factors come into play. The use of the body mass index (BMI), defined as the weight in kilograms divided by the square of height in meters, has been suggested as a possible indicator of household food availability (James and others, 1999). It seems reasonable to expect that changes in food availability, such as seasonal food shortages, would be reflected in a low BMI. As women tend to be the most vulnerable household members, their BMI has been chosen as a proxy for household food availability. The cut off point of a BMI of less than 18.5 is generally regarded as an indicator of malnutrition, with a BMI of less than 16 regarded as a sign of severe malnutrition. A dummy variable, which takes a value of one if the mother's BMI is less than 18.5 is therefore used to proxy for household food insecurity.

Maternal education has been identified as a significant determinant of children's health in the literature. The analysis incorporates information on the education of the mother and her husband or partner. Eighty two percent of the women in the sample report receiving no formal education. Thirteen percent report at least some primary school. Given the low level of education in the sample, an additional year of education may be a significant factor and therefore the mother's education variable is defined as the number of years of education. The husband's or partner's level of education is also defined as the number of years of education. Nearly two-thirds of the men report no education, twenty percent report some primary education, and five percent report completing primary education.

Household composition may affect how household resources are distributed among household members. Therefore, variables on household size, whether the household is headed by a female, and the number of children under 5 years of age are used in the analysis. 


\section{$\underline{\text { Environmental factors }}$}

The environmental variables of interest in the current study are access to water and sanitation. Public health measures in developed countries, such as water purification, sanitary sewerage, trash and garbage collection, and reductions in food contamination, have led to a substantial decline in morbidity and mortality (Rustein, 2000). Removing contaminants from the living space of children in developing countries is an important means to improve children's health and prevent their deaths. Research also suggests that access to water impacts health not just through the quality of water that is drunk, but also due to increases in quantity available, which can be used for cleaning and hygienic behavior (such as washing hands) (Burger and Esrey, 1994).

Table 4 shows urban and rural households source of drinking water and type of sanitation facilities. Most previous studies on malnutrition have considered access to piped water in the dwelling as the definition of good water. However, in the rural areas in Ethiopia very few households have access to piped water. The five percent of rural households with access to piped water have to travel one hour, on average, to get to the water source. A significantly higher proportion of urban households - nearly 80 percent - have access to piped water in or outside their compound. In general, water obtained from surfaces sources, such as river, lake, pond or dam, is considered unsafe (Rutstein, 2000). These sources are likely to be contaminated in an environment where there is a lack of sanitation facilities. As Table 4 shows, a significant proportion of the rural population obtain their drinking water from these surface sources. Given that ninety percent of the rural population does not have access to any toilet facility, these water sources are likely to be contaminated. The definition of "safe water" used in the analysis tries to capture both aspects of water quality and availability. It includes piped water - whether inside or outside of the compound - as well as water from a well, as long as access to those sources is less than 30 minutes away from the household. ${ }^{7}$

Less than one percent of households in our sample have a flush toilet or access to an improved ventilated latrine. There are considerable differences in access to sanitation between urban and rural households. Two thirds of urban households have access to some type of toilet

\footnotetext{
${ }^{7}$ Adding the restriction that water be from sources 30 minutes or less from the household has a significant impact on results but not at the individual level. It only affects the significance and coefficient of the proportion of households that have access to water.
} 
facility, primarily a traditional pit latrine. In contrast, over ninety percent of the rural population do not have access to any sanitation facilities. There is certainly a strong case to expect that access to sanitation brings about significant health benefits, as the proper disposal of human feces is likely to reduce the spread of infections diseases. However, the empirical literature on the effects of sanitation on child anthropometry and survival in developing countries is not conclusive (Gragnolati, 1999). This could in part be a result of the limited number of households with access to flushing toilets, which is often the definition of proper sanitation used in most studies. The lack of information on other determinants of a hygienic environment, such as the availability of garbage and human waste disposal sites, may also be a factor why the results in the literature concerning the effects of sanitation are not always consistent.

In trying to capture the overall sanitary environment surrounding a household this study takes into account the disparities in access between urban and rural population, as well as some behavioral information regarding how households dispose of children's stool. For urban households, proper sanitation is defined as access to a flush toilet or a latrine. For rural households, this definition is expanded to also take into account whether the household disposes of children's stool properly, since that is likely to affect the household and its neighboring environment. Sanitary conditions are more likely when children's stools are thrown into a toilet, latrine, or buried into the yard. Unsanitary disposal includes throwing the stool outside the dwelling or yard, or rinsing it away. ${ }^{8}$

Table 4. Water and sanitation access

\begin{tabular}{lccc}
\hline & Full Sample & Urban & Rural \\
\hline Source of drinking water & & & \\
Piped into dwelling & 0.11 & 1.04 & 0.00 \\
Piped into compound & 2.04 & 19.58 & 0.00 \\
Piped outside compound & 11.01 & 59.03 & 5.44 \\
Open well & 3.50 & 1.41 & 3.75 \\
Open spring & 42.10 & 4.77 & 46.43 \\
& & \\
& & \\
${ }^{8}$ This is in line with the sanitation definition adopted by Alderman, Hentschel, and Sabates (2002), which \\
excluded the types of situation where unhygienic treatment of human waste may occur due to the use of shared \\
facilities, facilities not connect to a public net or septic tank, and open disposal human waste in canals, roads, \\
etc.
\end{tabular}


Covered well

Covered spring

River

Pond/lake/dam

Rainwater or other

Type of toilet facility

Flush toilet

Improved (ventilated) latrine

Traditional pit latrine

No facility, bush, field
2.75

5.42

28.87

4.15

0.06

0.16

0.29

13.72

85.83
2.44

2.80

8.81

0.00

0.11

1.57

2.03

63.11

33.28
2.79

5.72

31.19

4.63

0.05

Of particular interest in this investigation are the possible external effects of other household's investments and its impact on the common neighborhood environment. To capture these "neighborhood effects" variables with the average level of education and wealth, and the proportion of households with access to safe water and sanitation are created. These averages are obtained from the non-self means of the respective variables, which are calculated by summing the variable of interest over the sample cluster and then subtracting the observation from the household and dividing this difference by the number of households in the cluster minus one. ${ }^{9}$

The proportion of households with access to safe water in a given location may be largely determined by geographical and climatic factors. Households living in the highlands, where peaks are as high as 4,550 meters above seal level, face very different constraints from those living in areas 110 meters below sea level, such as the Afar Depression. Altitude measurements were taken using a global positioning device for each of the survey clusters and are included in the analysis.

\section{Econometric Specification}

This study examines the impact of the above variables on the probability a child is stunted and underweight. This choice for the dependent variable, rather than the actual $\mathrm{Z}$ scores, facilitates interpretation of the results, as most measures of malnutrition are reported as the proportion of children who fall in these categories. A child is stunted $(y=1)$ if his or her

\footnotetext{
${ }^{9}$ The clusters in the sample are relatively small and therefore it is likely the standard errors are large. This would bias parameters towards zero.
} 
standardized height for age $\mathrm{Z}$ score falls two standard deviations or more below the standard population mean. Similarly a child is underweight $(\mathrm{y}=1)$ if the child's weight for age $\mathrm{Z}$ score falls two standard deviations or more below the standard population mean. Otherwise, $y=0$. The vector $x$ represents the variables discussed above. The regression equation can therefore be written as:

$$
\begin{aligned}
& \operatorname{Prob}(y=1)=F\left(\beta^{\prime} x_{i}\right) \\
& \operatorname{Prob}(y=0)=1-F\left(\beta^{\prime} x_{i}\right)
\end{aligned}
$$

Under the assumption that in a well-nourished population the distribution of children's height and weight at a given age follows a normal distribution, the probability a child is stunted or underweight is given by:

$$
\operatorname{Prob}(y=1)=\int_{\infty}^{\beta^{\prime} x_{i}} \phi(t) d t
$$

or with the function $\Phi$ used as a notation for the cumulative standard normal distribution,

$$
\operatorname{Prob}(y=1)=\Phi\left(\beta^{\prime} x_{i}\right)
$$

The model is estimated by the method of maximum likelihood, as with ordinary least squares $\beta^{\prime} x$ cannot be constrained to the $0-1$ interval and the estimation could produce both nonsense probabilities and negative variances. The joint probability function, or likelihood function, with independent observations can be written as:

$$
\operatorname{Prob}\left(Y_{1}=y_{1}, Y_{2}=y_{2}, \ldots, Y_{n}=y_{n}\right)=\Pi_{y=0}\left(1-\Phi\left(\beta^{\prime} x_{i}\right)\right) \Pi_{y=1} \Phi\left(\beta^{\prime} x_{i}\right)
$$

or,

$$
L=\prod_{i=1}^{n}\left(1-\Phi\left(\beta^{\prime} x_{i}\right)\right)^{y},\left(\Phi\left(\beta^{\prime} x_{i}\right)\right)^{1-y_{i}}
$$

Taking the log of both sides, we obtain

$$
\ln L=\sum_{i=1}^{n}\left[y_{i} \ln \Phi\left(\beta^{\prime} x_{i}\right)+\left(1-y_{i}\right) \ln \left(1-\Phi\left(\beta^{\prime} x_{i}\right)\right)\right]
$$

And the first order conditions for a maximum are given by ${ }^{10}$ :

\footnotetext{
${ }^{10}$ The proof that second order conditions for a maximum hold (i.e., the hessian matrix is negative definite) is provided in Greene (1997).
} 


$$
\frac{\partial \ln L}{\partial \beta}=\sum_{i=1}^{n}\left[\frac{y_{i} \phi\left(\beta^{\prime} x_{i}\right)}{\Phi\left(\beta x_{i}\right)}+\left(1-y_{i}\right) \frac{-\phi\left(\beta^{\prime} x_{i}\right)}{1-\Phi\left(\beta^{\prime} x_{i}\right)}\right] x_{i}=0
$$

The two-stage sampling design of the DHS and most other household surveys, however, violates the assumption of independent observations. Households in a given cluster are more likely to be similar to one another in some respects than households in different clusters. The weighted or unweighted mean of variables are not affected by the two-stage design, but the design does increase the variability of these estimates compared with a simple random sampling design. If the sample design is ignored, the variance of estimated means using standard formulas will be too small. In addition, since the error terms in the regression are correlated across observations in the same cluster, without some procedure to correct these standard errors, the efficiency of the coefficients estimated will be affected (Deaton, 1997).

Unless one fully parameterizes the correlation within clusters, the true likelihood function for the clustered sample cannot be written. ${ }^{11}$ However, the model can be estimated without parameterization of the within-cluster correlation using appropriate statistical techniques. These will estimate the $\beta$ vector that maximizes the likelihood function that we would have if we had data on all individuals in the population. The variance estimates are computed as if the sample was drawn again and again using the same clustering scheme and the estimated $\beta$ vector computed as the maximum of the "pseudo-likelihood". ${ }^{12}$

Another issue of concern for the estimation of the above model is the possible endogeneity of some of the variables chosen as explanatory variables. For example, if household access to water or sanitation is a choice variable, then it may be correlated with the unobservables attributed to the error term. Endogeneity may also be a concern with the use the mother's BMI as a proxy for household food security. Failure to control for possible endogenous variables could lead to biased estimates. To test for the possibility of endogenous variables, two estimators can be compared, one consistent (and efficient) under the hypothesis that there is no endogeneity, but inconsistent if there is endogeneity, and the other consistent

\footnotetext{
${ }^{11}$ Gragnolati (1999) specifies a variance components model and a random coefficients model in his study of malnourished children in Guatemala.

${ }^{12}$ The STATA 7.0 manual contains a more detailed discussion of the survey estimation commands that can be used in this case.
} 
under both hypothesis (Kennedy, 1992). If there is no correlation between the regressors and the error term, then both estimators produce similar coefficient estimates. The Hausman test can be used to test the equality of the estimates produced by two different estimators. ${ }^{13}$ The more efficient estimator would be preferred if the Hausman test fails to reject its the consistency.

Instrumental variables (IV) estimation can provide consistent coefficient estimates, as long as a unique solution to the estimation problems exists and the instrumental variables are uncorrelated with the error term in the model (Davidson and MacKinnon, 2004). However, it is known that IV estimates can be generally biased as well, particularly if the instrumental variables used are weak predictors of the endogenous explanatory variables (Davidson and McKinnon, 2004; Bound, et al., 1995). Given the limited number of variables available in the data which could be used as potentially good instruments, we test for endogeneity by comparing the results with and without the inclusion of possible endogenous variables to determine whether there is evidence of any potential bias.

\section{Results}

The results of the analysis are presented separately for underweight and stunting in Table 5 and Table 6. The first column of each table reports the results of the model which includes mostly child and household specific characteristics, including household environmental conditions. The second columns adds the impact of community environmental conditions, which are constructed from the non-self cluster means for access to water, and sanitation. This specification also includes the non-self cluster means for female education level and the wealth index. The primary objective of the analysis is to investigate the impacts of community access to water and sanitation on the nutritional status of children. The last column restricts the sample to include only observations from the rural population, which constitutes about ninety percent of our sample.

\footnotetext{
${ }^{13}$ The assumption that one of the estimators is efficient is a demanding one. It is violated, for example, if observations are clustered, if probability weights are used, or if the model is somehow misspecified. Moreover, even if the efficiency assumption is satisfied, there may be a "small sample" problem. In some cases, the Hausman test may be undefined. However, a generalized Hausman test, which overcomes both of these problems, may be applicable (StataCorp. 2003).
} 
As expected, child's age, mother's height, household wealth, and mother's education are significant determinants of a child's nutritional status. We included the mother's height to control for a child's genetic endowment and the high significance of this coefficient would suggest that there is indeed an intergenerational effect. However, one would not expect the mother's height to directly influence the development of a child, and hence the child's nutritional status, which explains the small impact of this variable. The probability of a child being underweight or stunted increases significantly as the child gets older. Children between 12-23 months of age are at the highest risk of being malnourished and that risk remains very high as the child ages, particularly for stunting. The coefficient on the child's gender is not significant in any of the regressions, suggesting there are no gender bias affecting the nutritional status of children in Ethiopia. ${ }^{14}$

The impact of household wealth, as measured by the wealth index created, is to decrease the probability a child is underweight by about 4 percent and stunted by about 3 percent. We would generally expect a lower impact of current household wealth on stunting, as stunting is a measure of chronic malnutrition reflecting the impact of the households' current as much as past wealth.

Our proxy for household food insecurity, whether the mother's BMI is less than 18.5, is positive and significant in the equation for underweight, but not significant in the equation for stunting. ${ }^{15}$ Since a low BMI is a reflection of current nutritional status, it may not be a surprise that this measure of household food insecurity only affects the probability a child is underweight. As an indicator of household food insecurity, the coefficient on the BMI variable suggests that children in a household where the mother has a low BMI are about 6 percent more likely to be underweight. Children living in a female headed household are also 3 to 4 percent also more likely to be malnourished. The coefficient on household size is not significant in any of the regressions. The number of children under 5 years of age, however, has an adverse impact on the probability of a child being stunted but not underweight. It increases the probability of a child being stunted by 2.5 percent.

\footnotetext{
${ }^{14}$ Sahn and Stifel (2002) examine whether mother's schooling has a higher impact on daughter's than son's nutrition and whether father's education favors son's nutrition using DHS data for 14 African countries.

${ }^{15}$ The generalized Hausman test does not reject the consistency of the estimated model which includes the mother's BMI.
} 
The mother's education variable is highly significant but its impact on reducing the probability a child is malnourished is relatively small—only about 1.5 percent. This is probably a reflection of the very low level of female education in Ethiopia, particularly in rural areas. In contrast, the father's level of education is not significant in any of the equations. It is possible that the indirect effect of his education is already picked up by other variables, such as household wealth.

We now come to the results on the variables regarding access to water and sanitation, the primary focus of this paper. ${ }^{16}$ We first discuss the results of the specification which includes only measures of a household's own environmental conditions. While the coefficients for households' own access to water and sanitation in both the underweight and stunting equation are negative, as expected, these coefficients are small and not significant. The results for the model including community environmental conditions for the whole sample and for the rural sample are discussed next. The coefficients on the proportion of households with access to these services are highly significant in the underweight equations. The large coefficient on these variables suggests a significant spillover effect of other household's access to these services. These results, however, do not hold for stunting. Note also that the coefficients on the proportion of households with access to water and sanitation in the stunting equations are generally smaller. Trying to measure the impact of these variables on the proportion of children stunted can be a bit problematic, given that stunting is a reflection of chronic malnutrition. We only observe these variables at the time of the survey and therefore cannot account for their past impact on stunting.

We also find a significant external impact on stunting from female's education, as in the Alderman, Hentschel and Sabates (2002) study. However, this impact is small and does not hold for the probability of a child being underweight. Again, the weakness of the female education variable in this study is probably a reflection of the very low levels of education in Ethiopia. An alternative way to capture the role of knowledge would be to construct an indicator variable of "good care" practices relating to appropriate child feeding, preventive use of health facilities, knowledge of treatment options for common childhood illnesses. Ruel and others (1999) find that in some instances, these factors can mitigate the negative impacts

\footnotetext{
${ }^{16}$ The generalized Hausman test does not reject the consistency of the estimated model which includes the household's own access to water and sanitation.
} 
of poverty and low maternal education. This is beyond the scope of the current analysis, but may be an interesting alternative to pursue in future work. The variable on the community level of wealth is not significant, despite its significance at the individual level. Given the high rates of poverty in Ethiopia, a household based asset measure of community wealth may not be the best indicator of a community's general welfare.

Table 5: Determinants of underweight, probit estimates

\begin{tabular}{|c|c|c|c|c|c|c|}
\hline \multirow[b]{2}{*}{ Variables } & \multicolumn{2}{|c|}{$\begin{array}{l}\text { Household } \\
\text { Environmental } \\
\text { Conditions }\end{array}$} & \multicolumn{2}{|c|}{$\begin{array}{l}\text { Community } \\
\text { Environmental } \\
\text { Conditions }\end{array}$} & \multicolumn{2}{|c|}{$\begin{array}{c}\text { Community Env. } \\
\text { Conditions } \\
\text { (Rural Sample) }\end{array}$} \\
\hline & $\begin{array}{l}\text { Probability } \\
\text { coefficients }\end{array}$ & $\begin{array}{c}\text { Standard } \\
\text { Error }\end{array}$ & $\begin{array}{l}\text { Probability } \\
\text { coefficients }\end{array}$ & $\begin{array}{c}\text { Standard } \\
\text { Error }\end{array}$ & $\begin{array}{l}\text { Probability } \\
\text { coefficients }\end{array}$ & $\begin{array}{c}\text { Standard } \\
\text { Error }\end{array}$ \\
\hline \multicolumn{7}{|c|}{ Individual Characteristics } \\
\hline Female $^{\wedge}$ & 0.009 & 0.012 & 0.007 & 0.012 & 0.008 & 0.014 \\
\hline Age 6-11 months^ & $0.454^{* * *}$ & 0.027 & $0.453^{* * *}$ & 0.027 & $0.456^{* * *}$ & 0.026 \\
\hline Age 12-23months^ & $0.617^{* * *}$ & 0.020 & $0.616^{* * *}$ & 0.020 & $0.614^{* * *}$ & 0.019 \\
\hline Age $24-35$ months $^{\wedge}$ & $0.599^{* * *}$ & 0.021 & $0.598^{* * *}$ & 0.021 & $0.598^{* * *}$ & 0.020 \\
\hline Age $36-47$ months $^{\wedge}$ & $0.565^{\star * *}$ & 0.023 & $0.564^{* * *}$ & 0.023 & $0.568^{* * *}$ & 0.023 \\
\hline Age $47-59$ months $^{\wedge}$ & $0.574^{* * *}$ & 0.023 & $0.574^{* * *}$ & 0.023 & $0.572^{* * *}$ & 0.022 \\
\hline Mother's height & $-0.001^{* * *}$ & 0.000 & $-0.001^{* * *}$ & 0.000 & $-0.001^{* * *}$ & 0.000 \\
\hline \multicolumn{7}{|c|}{ Household Characteristics } \\
\hline Mother's BMI & $0.065^{\star *}$ & 0.027 & $0.064^{* *}$ & 0.027 & 0.043 & 0.029 \\
\hline Wealth index & $-0.042^{* * *}$ & 0.006 & $-0.044^{* * *}$ & 0.009 & $-0.037^{* *}$ & 0.016 \\
\hline Female head & $0.040^{* *}$ & 0.019 & $0.042^{* *}$ & 0.019 & $0.042^{*}$ & 0.022 \\
\hline Household size & 0.003 & 0.003 & 0.003 & 0.003 & 0.004 & 0.003 \\
\hline Children under 5 & 0.010 & 0.009 & 0.009 & 0.009 & 0.006 & 0.011 \\
\hline Mother's education & $-0.010^{* * *}$ & 0.004 & $-0.009^{\star *}$ & 0.004 & $-0.011^{* *}$ & 0.006 \\
\hline Father's education & 0.000 & 0.001 & 0.000 & 0.001 & -0.001 & 0.001 \\
\hline Water^ & -0.007 & 0.021 & 0.024 & 0.022 & 0.021 & 0.026 \\
\hline Sanitation $^{\wedge}$ & -0.023 & 0.016 & 0.007 & 0.017 & 0.014 & 0.019 \\
\hline \multicolumn{7}{|c|}{ Community Characteristics } \\
\hline$\%$ water & & & $-0.087^{* *}$ & 0.041 & $-0.109^{*}$ & 0.057 \\
\hline$\%$ sanitation & & & $-0.135^{\star * *}$ & 0.040 & $-0.136^{* * *}$ & 0.050 \\
\hline$\%$ female education & & & -0.003 & 0.008 & -0.013 & 0.017 \\
\hline$\%$ wealth index & & & -0.105 & 0.114 & 0.094 & 0.326 \\
\hline Urban & 0.027 & 0.033 & $0.132^{* * *}$ & 0.040 & & \\
\hline Altitude & $1.83 e^{-06}$ & 0.000 & $-3.57 e^{-06}$ & 0.000 & $-2.82 e^{-06}$ & 0.000 \\
\hline Log Likelihood & -4759.79 & & -4747.36 & & -4149.46 & \\
\hline
\end{tabular}

Notes:

For continuous variables, the probability coefficients measure the marginal change in probability at the variable's mean. For discrete variables (market by ${ }^{\wedge}$ ) these coefficients should be interpreted as the change in probability for a change of the dummy variable from 0 to 1 .

Robust standard errors, adjusted for clustering effect.

${ }^{* * *},{ }^{* *},{ }^{*}$ indicate significance at 99,95 , and 90 confidence levels, respectively

Coefficient of dummy variables for different regions not reported 
Table 6: Determinants of stunting, probit estimates

\begin{tabular}{|c|c|c|c|c|c|c|}
\hline \multirow[b]{2}{*}{ Variables } & \multicolumn{2}{|c|}{$\begin{array}{c}\text { Household } \\
\text { Environmental } \\
\text { Conditions } \\
\end{array}$} & \multicolumn{2}{|c|}{$\begin{array}{c}\text { Community } \\
\text { Environmental } \\
\text { Conditions }\end{array}$} & \multicolumn{2}{|c|}{$\begin{array}{c}\text { Community Env. } \\
\text { Conditions } \\
\text { (Rural Sample) }\end{array}$} \\
\hline & $\begin{array}{l}\text { Probability } \\
\text { coefficients }\end{array}$ & $\begin{array}{l}\text { Standard } \\
\text { Error }\end{array}$ & $\begin{array}{l}\text { Probability } \\
\text { coefficients }\end{array}$ & $\begin{array}{c}\text { Standard } \\
\text { Error }\end{array}$ & $\begin{array}{l}\text { Probability } \\
\text { coefficients }\end{array}$ & $\begin{array}{c}\text { Standard } \\
\text { Error }\end{array}$ \\
\hline \multicolumn{7}{|c|}{ Individual Characteristics } \\
\hline Female $^{\wedge}$ & 0.007 & 0.011 & 0.007 & 0.011 & -0.003 & 0.012 \\
\hline Age 6-11 months ${ }^{\wedge}$ & $0.297^{* * *}$ & 0.029 & $0.295^{* * *}$ & 0.029 & $0.312^{\star \star *}$ & 0.027 \\
\hline Age $12-23$ months $^{\wedge}$ & $0.547^{* * *}$ & 0.019 & $0.546^{* * *}$ & 0.020 & $0.541^{* * *}$ & 0.018 \\
\hline Age $24-35$ months $^{\wedge}$ & $0.528^{* * *}$ & 0.020 & $0.527^{* * *}$ & 0.020 & $0.527^{* * *}$ & 0.019 \\
\hline Age $36-47$ months $^{\wedge}$ & $0.563^{\star * *}$ & 0.019 & $0.562^{\star * *}$ & 0.019 & $0.555^{\star * *}$ & 0.019 \\
\hline Age $47-59$ months $^{\wedge}$ & $0.555^{\star * *}$ & 0.019 & $0.555^{\star * *}$ & 0.019 & $0.541^{* * *}$ & 0.018 \\
\hline Mother's height & $-0.001^{* * *}$ & 0.000 & $-0.001^{* * *}$ & 0.000 & $-0.001^{* * *}$ & 0.000 \\
\hline \multicolumn{7}{|c|}{ Household Characteristics } \\
\hline Mother's BMI & -0.022 & 0.029 & -0.022 & 0.029 & -0.039 & 0.015 \\
\hline Wealth index & $-0.028^{* * *}$ & 0.005 & $-0.026^{\star * *}$ & 0.008 & -0.007 & 0.030 \\
\hline Female head & 0.030 & 0.018 & $0.031^{*}$ & 0.018 & 0.022 & 0.020 \\
\hline Household size & -0.002 & 0.003 & -0.002 & 0.003 & -0.001 & 0.003 \\
\hline Children under 5 & $0.026^{* * *}$ & 0.009 & $0.025^{\star \star *}$ & 0.009 & $0.020^{*}$ & 0.010 \\
\hline Mother's education & $-0.016^{* * *}$ & 0.004 & $-0.014^{\star * *}$ & 0.004 & $-0.014^{* * *}$ & 0.005 \\
\hline Father's education & 0.000 & 0.001 & 0.000 & 0.001 & 0.001 & 0.001 \\
\hline Water^ & -0.011 & 0.021 & 0.022 & 0.024 & 0.003 & 0.029 \\
\hline Sanitation^ & $-0.031^{*}$ & 0.017 & -0.017 & 0.018 & 0.004 & 0.020 \\
\hline \multicolumn{7}{|c|}{ Community Characteristics } \\
\hline$\%$ water & & & -0.031 & 0.039 & -0.058 & 0.054 \\
\hline$\%$ sanitation & & & -0.058 & 0.040 & -0.062 & 0.047 \\
\hline$\%$ female education & & & $-0.015^{\star}$ & 0.008 & $-0.030^{*}$ & 0.017 \\
\hline$\%$ wealth index & & & -0.013 & 0.114 & 0.187 & 0.331 \\
\hline Urban & 0.028 & 0.033 & $0.098^{* *}$ & 0.041 & & \\
\hline Altitude & $2.67 e^{-05}$ & 0.000 & $2.49 e^{-05}$ & 0.000 & $2.17 e^{-05}$ & 0.000 \\
\hline$\underline{\text { Log Likelihood }}$ & -4793.99 & & -4789.11 & & -4129.64 & \\
\hline \multicolumn{7}{|l|}{ Notes: } \\
\hline \multicolumn{7}{|c|}{$\begin{array}{l}\text { For continuous variables, the probability coefficients measure the marginal change in probability at the } \\
\text { variable's mean. For discrete variables (market by }{ }^{\wedge} \text { ) these coefficients should be interpreted as the } \\
\text { change in probability for a change of the dummy variable from } 0 \text { to } 1 \text {. } \\
\text { Robust standard errors, adiusted for clustering effect. }\end{array}$} \\
\hline
\end{tabular}


Tables 7 and 8 explore the impact of externalities due to access to water and sanitation by splitting the sample according to the neighborhood level of access to these services. Alderman, Hentschel, and Sabates (2002) suggest these externalities should be larger at low neighborhood levels of access to these services. In their study, they find externalities exist until about half of the neighborhood has access to sanitation. We report the results for these externality impacts according to whether at most one-third, one-half, and two-thirds of the households in a cluster have access to water and sanitation. The results on Tables 7 and 8 are fairly consistent for both underweight and stunting outcomes.

When only one third of the population has access to water and sanitation, the spillover effect of those with access to water and sanitation are each considerably larger than when compared to the full sample results. For example, the spillover effect on Table 7 for water and sanitation is a decrease in the probability of being underweight of 37 and 44 percent, respectively. These coefficients are about 3 to 4 times larger than the coefficients reported on Table 5 above. As the level of access to these services approaches fifty percent of households, the spillover impact is only about twice as large as the benchmark. As more households obtain access to water and sanitation, the spillover effect for water is almost the same as in the benchmark case, while for sanitation, the impact is still somewhat higher.

The results reported on Table 8 for stunting are very similar. However, recall that on Table 6 , the external impact of access to water and sanitation on the probability of a child being stunted were not significant. In this case, therefore, we do not have a proper benchmark for comparison of these results. Yet, it is interesting to note how the results reported on Table 8 for these variables change as the level of access to water and sanitation increases. When the community level of access to water and sanitation are low, the external impact of these variables are large and significant. As the level of access increases, the coefficient on these variables gets smaller and less significant, repeating the same pattern observed for these variables in Table 7. Surprisingly, the coefficients on the variables measuring wealth become positive, and significant in the case of neighborhood wealth. 
Table 7:External impacts by level of access to water and sanitation for underweight

\begin{tabular}{|c|c|c|c|c|c|c|}
\hline \multirow[b]{2}{*}{ Variables } & \multicolumn{2}{|c|}{$33 \%$ access } & \multicolumn{2}{|c|}{$50 \%$ access } & \multicolumn{2}{|c|}{$66 \%$ access } \\
\hline & $\begin{array}{l}\text { Probability } \\
\text { coefficients }\end{array}$ & $\begin{array}{c}\text { Standard } \\
\text { Error }\end{array}$ & $\begin{array}{l}\text { Probability } \\
\text { coefficients }\end{array}$ & $\begin{array}{c}\text { Standard } \\
\text { Error }\end{array}$ & $\begin{array}{l}\text { Probability } \\
\text { coefficients }\end{array}$ & $\begin{array}{c}\text { Standard } \\
\text { Error }\end{array}$ \\
\hline \multicolumn{7}{|c|}{ Individual Characteristics } \\
\hline Female $^{\wedge}$ & -0.001 & 0.015 & 0.001 & 0.014 & 0.004 & 0.014 \\
\hline Age 6-11 months ${ }^{\wedge}$ & $0.449^{* * *}$ & 0.030 & $0.441^{* * *}$ & 0.028 & $0.456^{* * *}$ & 0.027 \\
\hline Age $12-23$ months ${ }^{\wedge}$ & $0.612^{* * *}$ & 0.022 & $0.606^{* * *}$ & 0.020 & $0.612^{* * *}$ & 0.019 \\
\hline Age $24-35$ months $^{\wedge}$ & $0.591^{* * *}$ & 0.023 & $0.587^{* * *}$ & 0.021 & $0.596^{* * *}$ & 0.02 \\
\hline Age $36-47$ months $^{\wedge}$ & $0.559^{* * *}$ & 0.026 & $0.556^{\star * *}$ & 0.024 & $0.565^{\star * \star}$ & 0.023 \\
\hline Age $47-59$ months $^{\wedge}$ & $0.573^{* * *}$ & 0.025 & $0.565^{* * *}$ & 0.023 & $0.573^{* * *}$ & 0.022 \\
\hline Mother's height & $-0.001^{* * *}$ & 0.000 & $-0.001^{* * *}$ & 0.000 & $-0.001^{* * *}$ & 0.000 \\
\hline \multicolumn{7}{|c|}{ Household Characteristics } \\
\hline Mother's BMI & $0.058^{*}$ & 0.033 & $0.059^{* *}$ & 0.030 & $0.055^{*}$ & 0.029 \\
\hline Wealth index & -0.027 & 0.020 & $-0.037^{* *}$ & 0.016 & $-0.038^{* * *}$ & 0.014 \\
\hline Female head & 0.028 & 0.025 & $0.042^{*}$ & 0.023 & $0.041^{*}$ & 0.022 \\
\hline Household size & 0.005 & 0.004 & 0.004 & 0.004 & 0.004 & 0.003 \\
\hline Children under 5 & -0.001 & 0.012 & 0.006 & 0.011 & 0.004 & 0.011 \\
\hline Mother's education & -0.004 & 0.006 & $-0.014^{* *}$ & 0.006 & $-0.015^{\star *}$ & 0.006 \\
\hline Father's education & -0.001 & 0.001 & -0.001 & 0.001 & -0.001 & 0.001 \\
\hline Water^ & 0.009 & 0.036 & 0.012 & 0.030 & 0.019 & 0.027 \\
\hline Sanitation^^ & 0.029 & 0.026 & 0.018 & 0.021 & 0.009 & 0.020 \\
\hline \multicolumn{7}{|c|}{ Community Characteristics } \\
\hline$\%$ water & $-0.366^{* * *}$ & 0.141 & $-0.179^{* *}$ & 0.089 & $-0.100^{* *}$ & 0.072 \\
\hline$\%$ sanitation & $-0.444^{* * *}$ & 0.124 & $-0.245^{\star * *}$ & 0.076 & $-0.199^{* * *}$ & 0.060 \\
\hline$\%$ female education & -0.009 & 0.021 & -0.003 & 0.018 & -0.002 & 0.016 \\
\hline$\%$ wealth index & 0.411 & 0.416 & 0.122 & 0.297 & 0.000 & 0.257 \\
\hline Urban & 0.113 & 0.098 & $0.189^{* * *}$ & 0.062 & $0.131^{\star * *}$ & 0.051 \\
\hline Altitude & $-1.99 e^{-05}$ & 0.000 & $-3.35 e^{-06}$ & 0.000 & $2.09 \mathrm{e}^{-07}$ & 0.000 \\
\hline Log Likelihood & -3078.94 & & -3733.04 & & -3992.91 & \\
\hline
\end{tabular}

Notes:

For continuous variables, the probability coefficients measure the marginal change in probability at the variable's mean. For discrete variables (market by ${ }^{\wedge}$ ) these coefficients should be interpreted as the change in probability for a change of the dummy variable from 0 to 1.

Robust standard errors, adjusted for clustering effect.

$* * *,{ }^{* *},{ }^{*}$ indicate significance at 99,95 , and 90 confidence levels, respectively

Coefficient of dummy variables for different regions not reported 
Table 8: External impacts by level of access to water and sanitation for stunting

\begin{tabular}{|c|c|c|c|c|c|c|}
\hline \multirow[b]{2}{*}{ Variables } & \multicolumn{2}{|c|}{$33 \%$ access } & \multicolumn{2}{|c|}{$50 \%$ access } & \multicolumn{2}{|c|}{$66 \%$ access } \\
\hline & $\begin{array}{l}\text { Probability } \\
\text { coefficients }\end{array}$ & $\begin{array}{c}\text { Standard } \\
\text { Error }\end{array}$ & $\begin{array}{l}\text { Probability } \\
\text { coefficients }\end{array}$ & $\begin{array}{l}\text { Standard } \\
\text { Error }\end{array}$ & $\begin{array}{l}\text { Probability } \\
\text { coefficients }\end{array}$ & $\begin{array}{c}\text { Standard } \\
\text { Error }\end{array}$ \\
\hline \multicolumn{7}{|c|}{ Individual Characteristics } \\
\hline Female $^{\wedge}$ & -0.001 & 0.014 & -0.004 & 0.013 & -0.006 & 0.012 \\
\hline Age 6-11 months^ & $0.315^{\star * *}$ & 0.032 & $0.319^{* * *}$ & 0.030 & $0.313^{* * *}$ & 0.029 \\
\hline Age $12-23$ months ${ }^{\wedge}$ & $0.538^{* * *}$ & 0.022 & $0.542^{* * *}$ & 0.020 & $0.541^{* * *}$ & 0.019 \\
\hline Age $24-35$ months ${ }^{\wedge}$ & $0.524^{* * *}$ & 0.022 & $0.530^{* * *}$ & 0.020 & $0.528^{\star * *}$ & 0.020 \\
\hline Age $36-47$ months $^{\wedge}$ & $0.548^{* * *}$ & 0.022 & $0.558^{* * *}$ & 0.020 & $0.557^{* * *}$ & 0.019 \\
\hline Age $47-59$ months $^{\wedge}$ & $0.538^{* * *}$ & 0.022 & $0.543^{* * *}$ & 0.020 & $0.543^{* * *}$ & 0.019 \\
\hline Mother's height & $-0.001^{* * *}$ & 0.000 & $-0.001^{* * *}$ & 0.000 & $-0.001^{* * *}$ & 0.000 \\
\hline \multicolumn{7}{|c|}{ Household Characteristics } \\
\hline Mother's BMI & -0.030 & 0.035 & -0.021 & 0.033 & -0.027 & 0.032 \\
\hline Wealth index & 0.010 & 0.019 & 0.014 & 0.016 & 0.010 & 0.014 \\
\hline Female head & 0.017 & 0.024 & 0.018 & 0.022 & 0.025 & 0.021 \\
\hline Household size & 0.001 & 0.004 & 0.000 & 0.004 & 0.000 & 0.003 \\
\hline Children under 5 & 0.018 & 0.012 & $0.021^{*}$ & 0.011 & $0.021^{* *}$ & 0.010 \\
\hline Mother's education & $-0.012^{*}$ & 0.006 & $-0.017^{* * *}$ & 0.006 & $-0.019^{* * *}$ & 0.006 \\
\hline Father's education & $0.001^{*}$ & 0.001 & 0.001 & 0.001 & 0.001 & 0.001 \\
\hline Water^ & 0.017 & 0.041 & 0.014 & 0.033 & 0.007 & 0.031 \\
\hline Sanitation $^{\wedge}$ & 0.014 & 0.029 & 0.022 & 0.023 & 0.008 & 0.021 \\
\hline \multicolumn{7}{|c|}{ Community Characteristics } \\
\hline$\%$ water & $-0.326^{\star * *}$ & 0.120 & -0.122 & 0.077 & -0.084 & 0.065 \\
\hline$\%$ sanitation & $-0.246^{* *}$ & 0.108 & $-0.145^{* *}$ & 0.070 & $-0.108^{*}$ & 0.059 \\
\hline$\%$ female education & -0.023 & 0.020 & -0.026 & 0.018 & -0.024 & 0.016 \\
\hline$\%$ wealth index & 0.505 & 0.376 & $0.665^{\star *}$ & 0.318 & $0.599^{* *}$ & 0.255 \\
\hline Urban & 0.022 & 0.071 & $0.116^{*}$ & 0.069 & 0.039 & 0.065 \\
\hline Altitude & $2.96 \mathrm{e}^{-06}$ & 0.000 & $1.69 e^{-05}$ & 0.000 & $1.50 e^{-05}$ & 0.000 \\
\hline Log Likelihood & -3073.41 & & -3702.51 & & -3967.75 & \\
\hline
\end{tabular}

Notes:

For continuous variables, the probability coefficients measure the marginal change in probability at the variable's mean. For discrete variables (market by ${ }^{\wedge}$ ) these coefficients should be interpreted as the change in probability for a change of the dummy variable from 0 to 1 .

Robust standard errors, adjusted for clustering effect.

${ }^{* * *},{ }^{* *},{ }^{*}$ indicate significance at 99,95 , and 90 confidence levels, respectively

Coefficient of dummy variables for different regions not reported 


\section{Conclusion}

Malnutrition is a pervasive problem in Ethiopia and it is no doubt a direct consequence of widespread poverty. Analyzing the impact of different factors on children's malnutrition is further complicated by Ethiopia's vulnerability to frequent and severe droughts. Using demographic and health survey data, this study examines on the impact of access to basic environmental services, such as water and sanitation, on the probability children are stunted and underweight. The focus is on the impact of externalities associated with access to these services. Therefore, controlling for household access to these services, we look at how the proportion of households with access to these services in the community affects children's nutritional status.

We find that child's age, mother's height, household wealth and mother's education are important determinants of a child's nutritional status, which is consistent with the findings of most studies in this literature. The impact of mother's education, however, is small and probably mostly a reflection of the very low level of female education in Ethiopia. With respect to the environmental variables, we find that there are indeed significant externalities associated with access to water and sanitation at the community level. The external impacts of the community level of access to these services are an important determinant of the probability a child is underweight. Our results also show that the impact of access to water is larger for children living in rural areas.

As the proportion of households in the community with access to water and sanitation increases, the external impact on children's nutritional outcomes diminishes, as expected. The external impact of community access to water and sanitation on the probability a child is stunted is only significant when the proportion of households with access to these services is low. As the level of access increases, however, the coefficients on these variables become small and no longer significant. Stunting is a chronic condition and is likely to persist even after elimination of conditions that contribute to it - these results are likely then a reflection of these circumstances.

It is possible that unobserved variables, which are correlated with the community's level of access to water and sanitation, are partly driving these results. However, in the absence of available data to control for community's wealth, there is little we can do to 
address this possibility. Therefore, the results of this study should be interpreted with care. With the availability of geographic coordinates in the DHS data, as data collection and availability for Ethiopia improves, such problems could be addressed in future research. 
Table 9: Means and standard deviations for variables in this study

\begin{tabular}{|c|c|c|c|}
\hline Variable & Definition & Mean & Std Dev. \\
\hline Child stunted & $\begin{array}{l}=1 \text { if height for age } Z \text { score is two std } \\
\text { deviations below the std mean }\end{array}$ & 0.50 & 0.007 \\
\hline Child underweight & $\begin{array}{l}=1 \text { if weight for height } Z \text { score two is std } \\
\text { deviations below the std mean }\end{array}$ & 0.46 & 0.007 \\
\hline Female & $=1$ if female & 0.49 & 0.007 \\
\hline Age & Child's age, in months & 29.1 & 0.244 \\
\hline Mother's height & Height, in centimeters & 1,565 & 0.875 \\
\hline Mother's BMI & $=1$ if $\mathrm{BMI}<18.5$ & 0.06 & 0.003 \\
\hline Female head & $=1$ if female is the head of the household & 0.12 & 0.004 \\
\hline Household size & Household size & 6.13 & 0.03 \\
\hline Children under 5 & Number of children under 5 years of age & 1.85 & 0.009 \\
\hline Mother's education & Number of years in school & 0.82 & 0.027 \\
\hline Father's education & Number of years in school & 2.63 & 0.129 \\
\hline Safe water & $\begin{array}{l}=1 \text { if household has access to piped water, } \\
\text { well or spring water within } 30 \text { minutes } \\
\text { distance }\end{array}$ & 0.09 & 0.004 \\
\hline Sanitation & $\begin{array}{l}=1 \text { if household has flush toilet, pit latrine, or } \\
\text { ventilated pit latrine }\end{array}$ & 0.14 & 0.004 \\
\hline Disposal & $\begin{array}{l}=1 \text { if household disposes of children's stool in } \\
\text { toilet/latrine, or buries it in yard }\end{array}$ & 0.22 & 0.005 \\
\hline Urban & $=1$, if household lives in urban area & 0.10 & 0.014 \\
\hline Altitude & Altitude in meters, at center of village/cluster & 2,086 & 3.356 \\
\hline Sample size & 8023 & & \\
\hline
\end{tabular}




\section{Table 10: Correlation Coefficients}

\begin{tabular}{|c|c|c|c|c|c|c|c|c|c|c|c|c|c|c|c|}
\hline & underwt & t stunt & $\begin{array}{c}\text { mother's } \\
\text { height }\end{array}$ & bmi & wealth & hhsize & under5 & $\begin{array}{l}\text { mother's } \\
\text { education }\end{array}$ & $\begin{array}{l}\text { father's } \\
\text { education }\end{array}$ & $\begin{array}{l}\text { safe } \\
\text { water }\end{array}$ & sanitation & $\begin{array}{c}\text { mean } \\
\text { safe water }\end{array}$ & $\begin{array}{c}\text { mean } \\
\text { sanitation }\end{array}$ & $\begin{array}{c}\text { mean } \\
\text { education }\end{array}$ & $\begin{array}{l}\text { mean } \\
\text { wealth }\end{array}$ \\
\hline underwt & 1.00 & & & & & & & & & & & & & & \\
\hline $\begin{array}{l}\text { stunt } \\
\text { mother's }\end{array}$ & 0.57 & 1.00 & & & & & & & & & & & & & \\
\hline height & -0.09 & -0.13 & 1.00 & & & & & & & & & & & & \\
\hline bmi & 0.04 & -0.02 & 0.07 & 1.00 & & & & & & & & & & & \\
\hline wealth & -0.21 & -0.17 & 0.04 & -0.05 & 1.00 & & & & & & & & & & \\
\hline hhsize & -0.01 & 0.00 & 0.08 & 0.02 & 0.01 & 1.00 & & & & & & & & & \\
\hline $\begin{array}{l}\text { under5 } \\
\text { mother's }\end{array}$ & -0.01 & 0.00 & 0.07 & -0.01 & -0.06 & 0.43 & 1.00 & & & & & & & & \\
\hline $\begin{array}{l}\text { education } \\
\text { father's }\end{array}$ & -0.17 & -0.15 & 0.05 & -0.03 & 0.71 & -0.06 & -0.08 & 1.00 & & & & & & & \\
\hline education & -0.08 & -0.06 & 0.04 & -0.03 & 0.35 & -0.02 & -0.01 & 0.30 & 1.00 & & & & & & \\
\hline safe water & -0.06 & -0.05 & 0.03 & 0.02 & 0.21 & -0.05 & -0.03 & 0.15 & 0.06 & 1.00 & & & & & \\
\hline $\begin{array}{l}\text { sanitation } \\
\text { mean }\end{array}$ & -0.11 & -0.09 & -0.01 & -0.03 & 0.48 & -0.01 & -0.04 & 0.37 & 0.18 & 0.13 & 1.00 & & & & \\
\hline $\begin{array}{l}\text { safe water } \\
\text { mean }\end{array}$ & -0.11 & -0.09 & 0.07 & 0.01 & 0.38 & -0.03 & -0.05 & 0.25 & 0.12 & 0.60 & 0.23 & 1.00 & & & \\
\hline $\begin{array}{l}\text { sanitation } \\
\text { mean }\end{array}$ & -0.16 & -0.13 & -0.03 & -0.03 & 0.61 & -0.03 & -0.07 & 0.46 & 0.22 & 0.22 & 0.66 & 0.34 & 1.00 & & \\
\hline $\begin{array}{l}\text { education } \\
\text { mean }\end{array}$ & -0.18 & -0.15 & 0.01 & -0.03 & 0.76 & -0.03 & -0.09 & 0.66 & 0.28 & 0.22 & 0.44 & 0.33 & 0.64 & 1.00 & \\
\hline wealth & 0.05 & 0.05 & -0.04 & 0.01 & -0.40 & -0.04 & -0.02 & -0.23 & -0.12 & 0.063 & -0.09 & -0.03 & -0.00 & 0.02 & 1.00 \\
\hline
\end{tabular}




\section{Appendix}

This appendix provides an overview of how to convert probit scores into changes in probability.

We define the probit model by:

$$
\operatorname{Prob}(Y=1)=F\left(\beta^{\prime} x\right)
$$

Since $\beta$ 'x has a normal distribution,

$$
\operatorname{Prob}\left(Y^{\prime}=1\right)=\Phi\left(\beta^{\prime} \mathrm{x}\right)
$$

Suppose the result for a probit regression is given by:

$$
\operatorname{Prob}(\mathrm{Y}=1)=\Phi\left(\beta_{1} \mathrm{x}_{1}+\beta_{2} \mathrm{X}_{2}+\alpha\right)
$$

The interpretation of $\beta_{1}$ in terms of the probit index function is that a one unit increase in $\mathrm{x}_{1}$ leads to an increase in the probit index by $\beta_{1}$ standard deviations. Intuitively, to transform the results in terms of changes in probability, we can take as a starting point the mean values of $\mathrm{x}_{1}$ and $x_{2}$, which we denote by $\chi_{1}$ and $\chi_{2}$, respectively. The corresponding probability calculated at the mean, is given by $\Phi\left(\beta_{1} \chi_{1}+\beta_{2} \chi_{2}+\alpha\right)$. To calculate the impact of a one unit change in $\mathrm{x}_{1}$, we evaluate $\Phi\left(\beta_{1}+\beta_{1} \chi_{1}+\beta_{2} \chi_{2}+\alpha\right)$ and subtract from it $\Phi\left(\beta_{1} \chi_{1}+\beta_{2} \chi_{2}+\alpha\right)$. The results presented above are in terms of the change in probabilities evaluated at the mean, which STATA automatically calculates when using the dprobit command. 


\section{References}

Alderman, H., J. Hentschel, and R. Sabates. 2003. "With the Help of One's Neighbor: Externalities in the Production of Nutrition in Peru." Social Science and Medicine, 56:10, pp.2019-2031.

Alderman, H., and M. Garcia. 1994. "Food Security and Health Security: Explaining the Levels of Nutritional Status in Pakistan." Economic Development and Cultural Change, 42, pp. 485-507.

Bond, J., D.A. Jaeger, and R.M. Baker. 1995. Problems with Instrumental Variables Estimation When the Correlation Between the Instruments and the Exogenous Explanatory Variables is Weak. Journal of the American Statistical Association 90, 443-450.

Central Statistical Authority. 2001. Ethiopia Demographic and Health Survey 2000. Addis Ababa, Ethiopia and Calverton, Maryland USA: Central Statistical Authority and ORC Macro.

Christiaensen, L., and H. Alderman. 2001. "Child Malnutrition in Ethiopia: Can Maternal Knowledge Augment the Role of Income?" African Region Working Paper Series No.22. The World Bank.

Curtis, S., and M. Hossain. 1998. "The Effect of Aridity Zone on Child Nutritional Status." West Africa Spatial Analysis Prototype. ORC Macro International.

Davidson, R. and J.G. MacKinnon. 2004. Econometric Theory and Methods. Oxford: Oxford University Press.

Deaton, A. 1997. The Analysis of Household Surveys: A Microeconometric Approach to Development Policy. Washington, D.C.: John Hopkins University Press and World Bank.

Engle, P., P. Menon, and L. Haddad. 1997. Care and Nutrition: Concepts and Measurement. Washington, D.C.: International Food Policy Research Institute.

Filmer, D., and L. Pritchett. 2001. "Estimating Wealth Effects Without Expenditure Data or Tears: An Application to Education Enrollments in States of India." Demography, 38:1, pp.115-132.

Fujii, T., S. Alayon, L. Montana. 2002. "Micro-level Estimation of the Prevalence of Stunting and Underweight Among Children in Cambodia." Draft Report prepared for The World Food Program and ORC Macro.

Garrett, J., and M. Ruel. 1999. "Are Determinants of Rural and Urban Food Security and Nutritional Status Different? Some Insights from Mozambique.” World Development, 27:11, pp.1955-1975.

Glewwe, P. 1999. "Why Does Mother's Schooling Raise Child Health in Developing Countries? Evidence from Morocco." Journal of Human Resources, 34:1, pp.124-139.

Gragnolati, M. 1999. "Children's Growth and Poverty in Rural Guatemala." Latin American and the Caribbean Region Human Development Sector Unit, Policy Research Working Paper No.2193. The World Bank.

Greene, W. 1997. Econometric Analysis. New Jersey: Prentice-Hall.

Haidar, J., and T. Demissie., 1999. "Nutrition Situation in Ethiopia.” South African Journal of Clinical Nutrition, 89:2, pp.181-183.

Huttly, S. 1990. "The Impact of Inadequate Sanitary Conditions on Health in Developing Countries." World Health Statistics Quarterly, 43, pp.????.

James, W., A. Ferro-Luzzi, S. Sette, and C. Mascie-Taylor. 1999. "The Potential Use of Maternal Size in Priority Setting When Combating Childhood Malnutrition." European Journal of Clinical Nutrition, 53, pp.112-119.

Jayne, T., J. Strauss, T. Yamano, and D. Molla. 2002. "Targeting Food Aid in Rural Ethiopia: Chronic Need or Inertia." Journal of Development Economics, 68, pp.247-288.

Kassouf, A., and B. Senauer. 1996. "Direct and Indirect Effects of Parental Education on Malnutrition among Children in Brazil: A Full Income Approach.” Economic Development and Cultural Change, 44:4, pp.817-838. 
Kennedy, P. 1992. A Guide to Econometrics. Oxford: Blackwell Publishers.

Kossman, J., P. Nestel, M. Herrera, A. Amin, and W. Fawzi. 2000. "Undernutrition in Relation to Childhood Infections: A Prospective Study in Sudan.” European Journal of Clinical Nutrition, 54, pp.463-472.

Madise, N., Z. Matthews, and B. Margetts. 1999. "Heterogeneity of Child Nutritional Status Between Households: A Comparison of Six Sub-Saharan African Countries." Population Studies, 53, pp.331-343.

Rice, A. L. Sacco, A. Hyder, and R. Black. 2000. "Malnutrition as an Underlying Cause of Childhood Deaths Associated with Infections Diseases in Developing Countries." Bulletin of the World Health Organization, 78:10, pp.1207-1221.

Ruel, M., C. Levin, M. Armar-Klemesu, D. Maxwell, and S. Morris. 1999. "Good Care Practices Can Mitigate the Negative Effects of Poverty and Low Maternal Schooling on children's Nutritional Status: Evidence from Accra." World Development, 27:11, pp.1993-2009.

Rutstein, S. 2000. "Factors Associated with Trends in Infant and Child Mortality in Developing Countries During the 1990's." Bulletin of the World Health Organization, 78:10, pp.1256-1270.

Sahn, D., and D. Stifel. 2002. "Parental Preferences for Nutrition of Boys and Girls: Evidence from Africa." Journal of Development Studies, 39:1, pp.21-45.

StataCorp. 2003. Stata Statistical Software: Release 8.0. Reference Manual. College Station, TX: Stata Corporation.

Smith, L., and L. Haddad. 1999. "Explaining Child Malnutrition in Developing Countries: A CrossCountry Analysis." Food Consumption and Nutrition Division Discussion Paper, International Food Policy Research Institute.

Takashi, Y., H. Alderman, and L. Christiaensen. 2003. "Child Growth, Shocks, and Food Aid in Rural Ethiopia." Paper presented at the DEC's Economists Forum, World Bank, April 10,2003.

Thomas, D., and J. Strauss. 1996. "Public Policy and Anthropometric Outcomes in the Cote d'Ivoire." Journal of Public Economics, 61, pp.155-192.

Thomas, D., and J. Strauss. 1992. "Prices, Infrastructure, Household Characteristics and Child Height." Journal of Development Economics, 39, pp.139-331.

Wolfe, B., and J. Behrman. 1982. "Determinants of Child Mortality, Health, and Nutrition in a Developing Country." Journal of Development Economics, 11, pp.163-193.

World Health Organization, 2002. The World Health Report: Reducing Risks, Promoting Healthy Life. Geneva: The World Health Organization. 